\title{
Autistic Spectrum Disorder and Mobile Applications: A Proposed Tool to Support Treatment
}

André Felipe Mendes Silva ${ }^{1}$, Bruna Lopes Santiago ${ }^{2}$, Catarina Luiza Santos Valentim ${ }^{3}$, Clara da Glória Diniz ${ }^{4}$, Daniel Vitor Dias Macedo ${ }^{5}$, Emmanuelle Tavares Cunha ${ }^{6}$, Laís

Leão Calumby ${ }^{7}$, Pedro Henrique Silva $\operatorname{Costa}^{8}$, Renata Oliveira Ferreira ${ }^{9}$, Edimar

Fagundes do Carmo ${ }^{10}$, Lázaro Lélis Tavares ${ }^{11}$, Renato da Silva ${ }^{12}$, Braulio Roberto Gomes Marinho Couto ${ }^{13}$, Diva Souza e Silva Rodrigues ${ }^{14}$, Luiz Melk de Carvalho ${ }^{15}$, Flávio Henrique Batista de Souza ${ }^{16 *}$

\author{
Centro Universitário de Belo Horizonte - UNIBH - Brazil \\ flabasouza@yahoo.com.br
}

\begin{abstract}
The United Nations Organization estimates that $1 \%$ of the world population has some degree of Autistic Spectrum Disorder (ASD). It makes family life distressing and such situation can be aggravated when the child/youth needs to enter the school environment and continue their monitoring. Based on that, this paper proposes to present a solution, conceived through the use of Mobile solution technologies, cloud computing and data analysis, to help the treatment of ASD patients. In its development, a mobile application was implemented to establish an interconnection between parents (or guardians), doctors and teachers. The solution works as follows: everyone involved is registered in the application, where the doctor can insert the drugs that are used and link to each patient; whereas parents and teachers can use an alarm-like functionality to discreetly record occurrences of crises and classify them according to their intensity. As a form of intelligent management of treatment, the doctor has a consolidation of "where", "when" and "what was the intensity of the crises" that the patient had. In parallel, via cloud computing, the data are consolidated into graphical analyzes with statistics per patient and per doctor to evaluate the effectiveness and efficiency of proposed treatments.
\end{abstract}

Keywords: autism spectrum disorder, mobile solutions, social living, cloud computing, treatment support. 


\section{$3^{\text {rd }}$ International Conference on Research in SCIENCE, ENGINEERING AND TECHNOLOGY}

11-13 March, 2021

Oxford - United Kingdom

\section{Introduction}

Technological advances in medicine over time are relevant, interfering both in the lives of patients and in the performance of professionals in the field, with a considerable impact on research and providing progress in the health field (Loncar-Turukalo et al., 2019). The use of technologies such as cloud computing and mobile applications has permeated this area (Stoyanov et al., 2015). There are several applications on the market that focus on well-being. It is possible to easily find options of applications focused on the aid of physical exercises, cardiac monitoring, mental stimuli and many others. With this it can be proved that the market has great space for this technology. In addition, it has increasingly become an aid in medical treatments (Meyer et al., 2018).

The support provided by mobile technology relies on interoperability with other available resources, such as Cloud Computing technology, which according to Varghese \& Buyya (2018) allows the user to be able to access data through computers, cell phones or tablets.

Therefore, Cloud Computing is characterized as an online service, which does not require installation. This makes it more accessible and saves space, connectivity from anywhere, centralizes information and other benefits.

The technologies analyzed so far enable the use of a third tool of considerable importance, Data Analysis. It is a method of analyzing data collected in an intelligent way, making it possible to see behaviors, changes in daily activities, and finding flaws in the executed process.

According to Sim (2019) the use of mobile devices has come over the years, occupying more space in society, the growth of mobile devices has taken a large part of the market, being considered a pocket computer for its practicality in obtaining quick access to information and applications. Thus, developing applications for mobile devices represents a more effective way to reach the target audience.

Through the use of mobile applications, Cloud Computing and Data Analysis, it is possible to develop a scalable tool to help in the treatment / care of patients' lives. Thus, this intention is the general objective of this article, focusing on children with Autism Spectrum Disorder. The solution seeks to bring together the personas who are directly involved in the day-to-day of the patient such as the family, teachers and the doctor in charge. Through a mobile tool, the structure provides analysis of treatments, medicines, and monitoring of the effects of treatments.

Autistic Spectrum Disorder (ASD) encompasses different conditions marked by disorders of neurological development, all of which are related to difficulties in social relationships, such as: difficulty in communication, interaction and repetitive and restrictive behavior patterns. Autism was considered a rare condition, which affects one out of every 2 thousand children in the Brazilian scenario (Onzi \& Gomes, 2015). This work is justified by the high demand for intelligent solutions that are updated to help and aid the analysis of the behavior of patients with Autistic Spectrum Disorder. 


\section{Methods}

This project started by raising the necessary demands for the treatment of patients with autistic spectrum disorder (ASD) in their social context.

With the initial demands projected by the team, the APP was initially modeled and implemented, that is, within the demands outlined by the medical team using the platforms according to section 3.2 .

Then, using the APP, data were consolidated, collected by the platform and stored in the cloud, so that it is possible to provision data for a Data Analysis process, capable of guiding treatment strategies.

The platform gives the doctor the patient daily contact feasibility, which with the possession of the data, information, graphs and reports can be collected and analyzed. So that they can optimize the patient management process, both with the responsible physician and with a team.

\section{Results}

\subsection{Mobile Solution}

The demonstration in figure 1 shows the structure of the application. Such an organization chart exactly matches the form of the proposed solution. The utilization process is carried out through the selection of the user profile, among them being: doctor, responsible and teacher. This selection defines the type of relationship the user will have with the patient.

From the choice of the application user, there are three usage flows, as is shown in Figure 1.

Figure 1: Structural diagram of the app

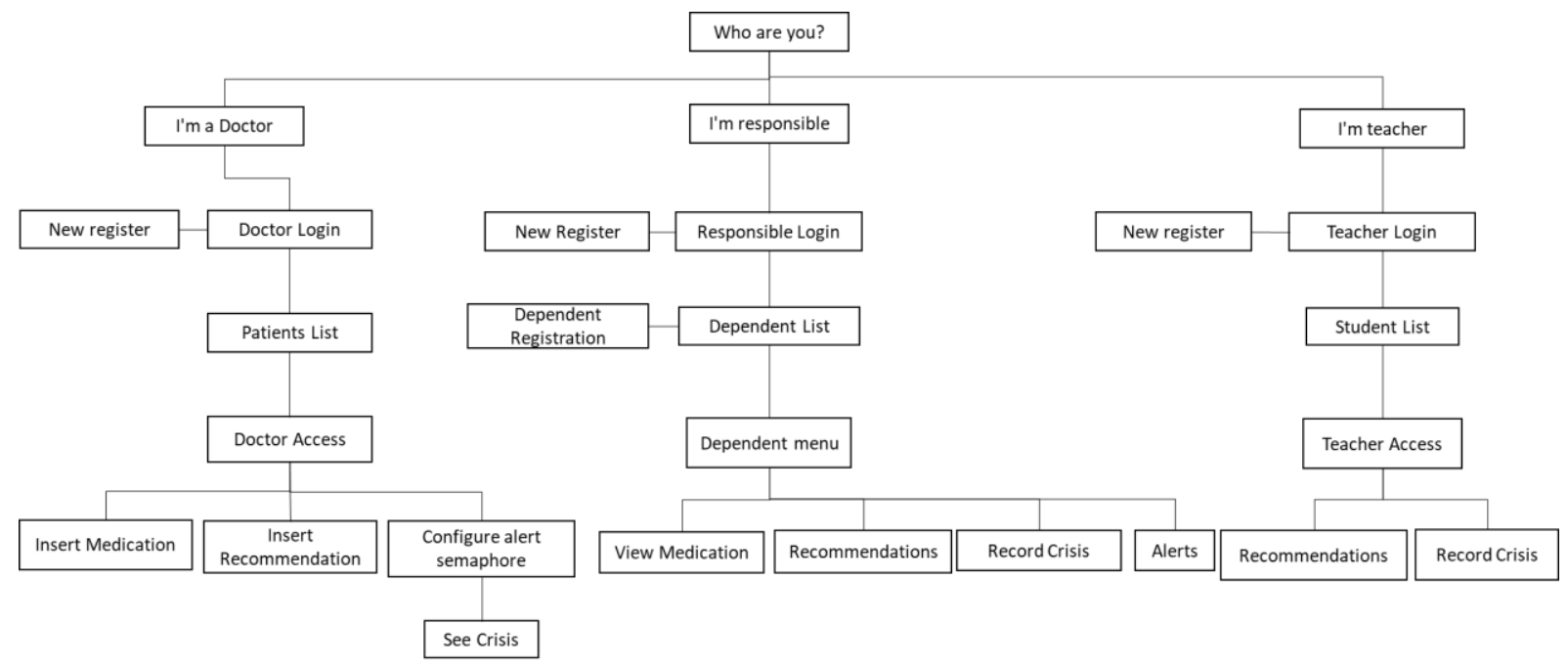




\section{$3^{\text {rd }}$ International Conference on Research in SCIENCE, ENGINEERING AND TECHNOLOGY}

11-13 March, 2021

Oxford - United Kingdom

Source: Authors, 2020

Firstly, the responsible use flow was defined. Once defined as responsible, it will be necessary to register by defining name, contact, email, password (confirming it) or log in if the user already has access. Then, the user will register a dependent to accompany the patient in a more dynamic way. After registering the dependent and informing their personal data for other users to obtain this information, the user will link the Doctor to the patient, also having access to the recommendations and medications prescribed by the doctor. It is not be possible to edit these fields as it will be defined by the Doctor. The user is able to issue crisis alerts so that the doctor can obtain a more detailed monitoring as can be seen in the flow of figure 2.

Then the flow of use of the doctor was defined. According to the explicit flow in figure 3 , after defining the relationship with the child as a doctor, at the first access it will be necessary to perform a registration to inform: name, CRM (Conselho Regional de Medicina - Regional Council of Medicine), password (making the confirmation). Once that is done, the doctor will have access to the list of patients who have the disorder. When selecting one of the patients, the doctor will have access to information, such as crises, medications and recommendations. The doctor, through an analysis, will be able to inform the medication so that they can define specific dosages and details of that medication; specific recommendations for each patient can be included; view the patient's crisis alerts, so that the doctor can have a more careful assessment in relation to current crises, types of crises and recommended medications so that it is possible to observe and monitor the evolution of the patient's condition.

Figure 2: Flowchart of use of the Responsible

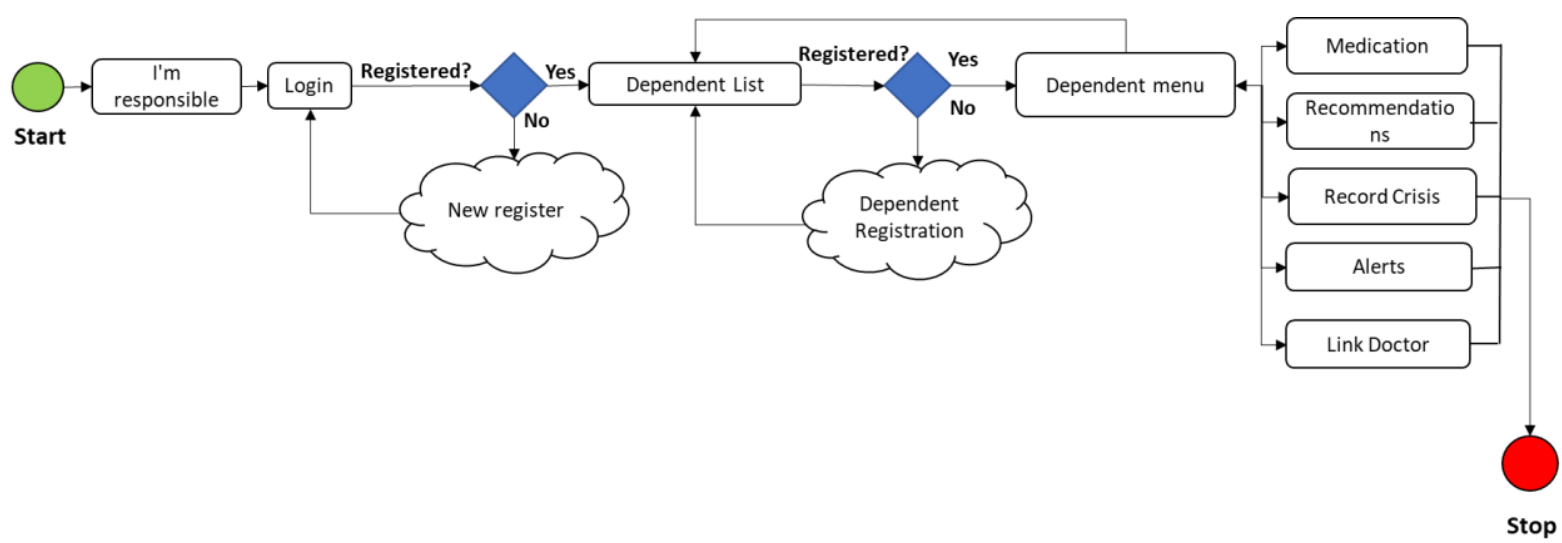

Source: Authors, 2020

The doctor can define how many occurrences are necessary to change the colors of the crisis status, as an example: if it is from 0 to 5 it will remain Green, 6 to 10 will be changed to Yellow and above 10 it will be Red, indicating that the treatment is not being effective for this patient. 


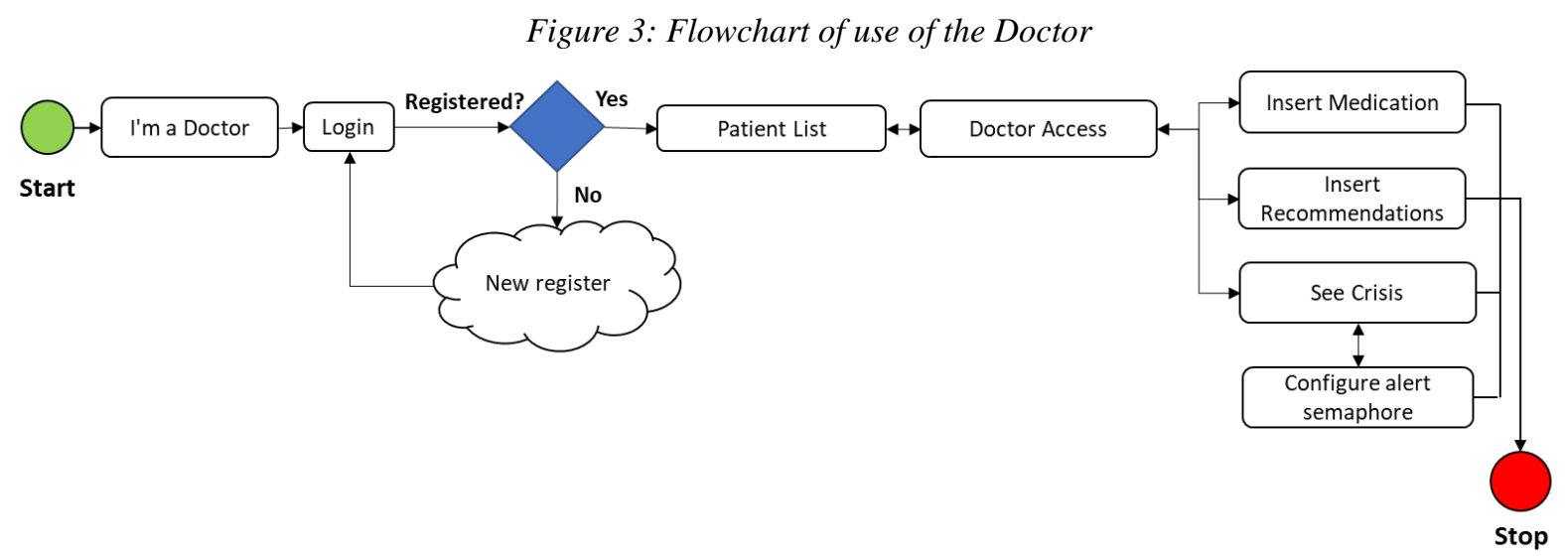

Source: Authors, 2020

Finally, the flow of use of the teacher was defined. The teacher, in turn, will log in with their email and password. If the teacher does not have access to the platform, registration will be necessary, informing data such as name of the institution, name of the teacher, an access login and password (confirming it). After confirming the login, the teacher will have access to their list of students (patients). When selecting a student, the teacher will have access to view information such as medical recommendations and will be able to issue crisis alerts for any student with the disorder, including data such as date, time, occurrence geolocation and posting an observation of such crisis. This case can be seen in the flow in figure 4 .

Besides the structural explanations on a case-by-case basis, it is also presented the application interfaces, which in turn exemplify the previous explaination with a more practical overview of the screen flow of the application The screens are presented in tables 1 to 4.

Figure 4: Flowchart of use of the Teacher

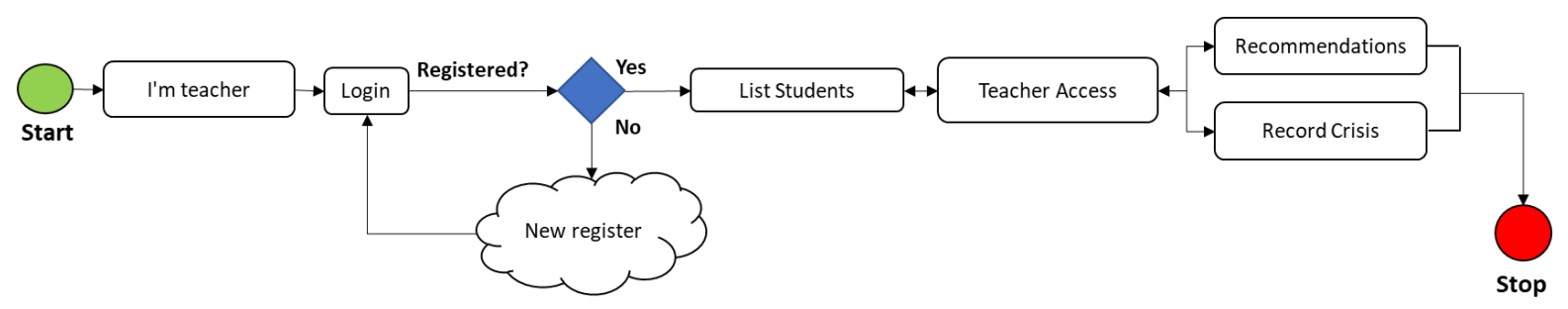

Source: Authors, 2020 


\section{$3^{\text {rd }}$ International Conference on Research in SCIENCE, ENGINEERING AND TECHNOLOGY}

\section{Ciset}

11-13 March, 2021

Oxford - United Kingdom

Table 1: Screenshots of the application screens (part 1)

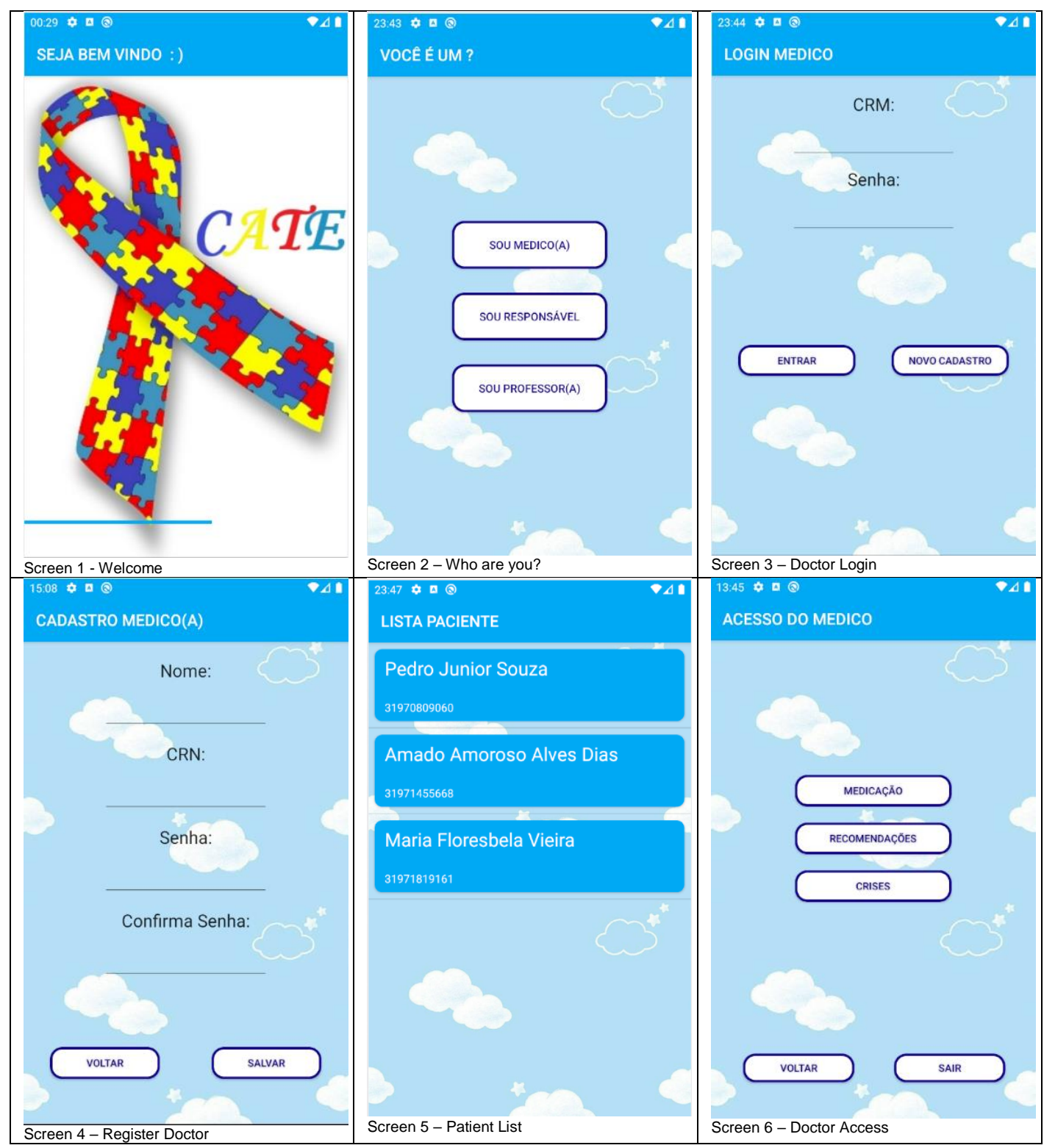

Source: Authors, 2020 


\section{$3^{\text {rd }}$ International Conference on Research in SCIENCE, ENGINEERING AND TECHNOLOGY}

11-13 March, 2021

Oxford - United Kingdom

Table 2: Screenshots of the application screens (part 2)

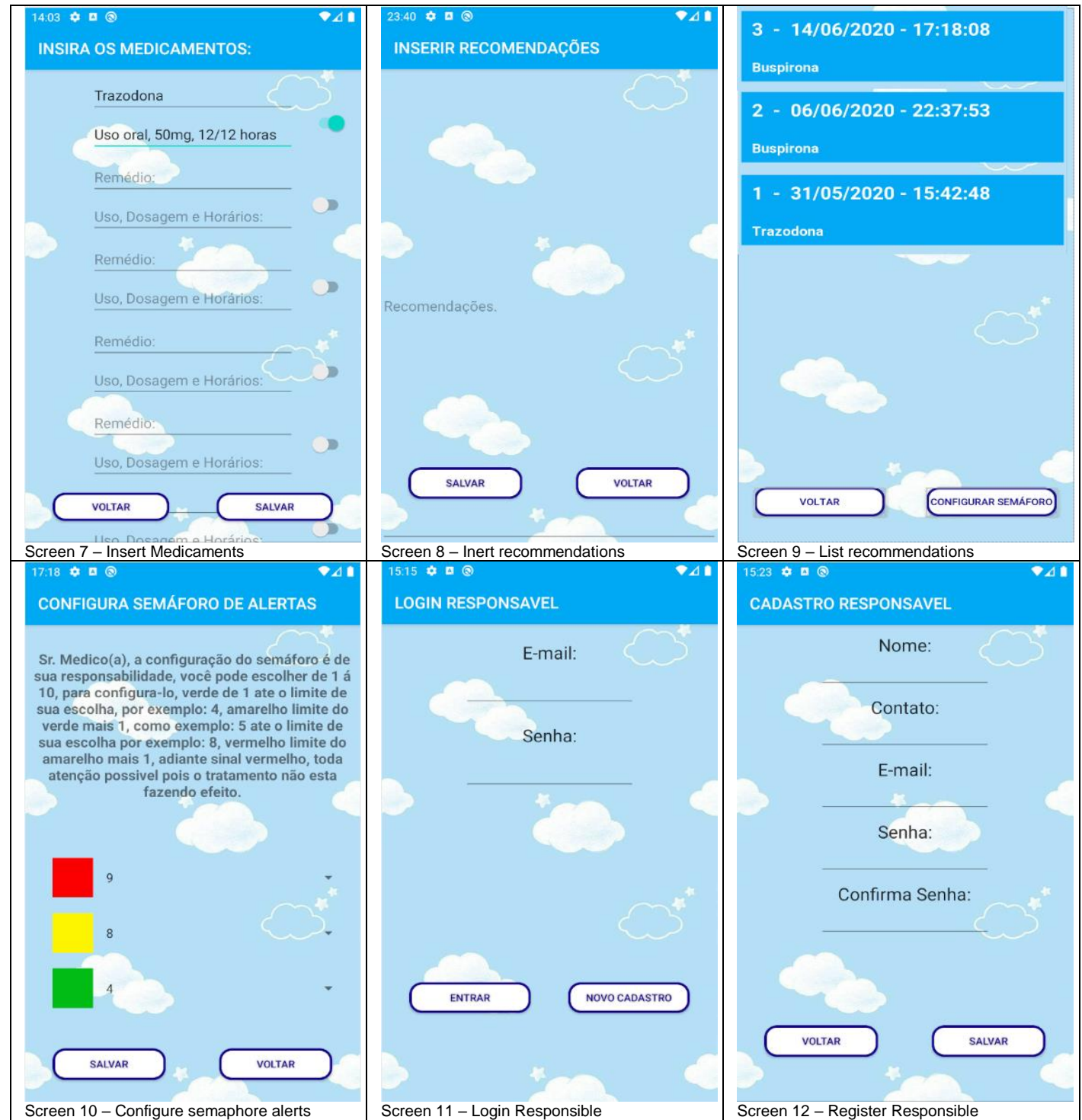




\section{$3^{\text {rd }}$ International Conference on Research in SCIENCE, ENGINEERING AND TECHNOLOGY}

\section{(ciset}

11-13 March, 2021

Oxford - United Kingdom

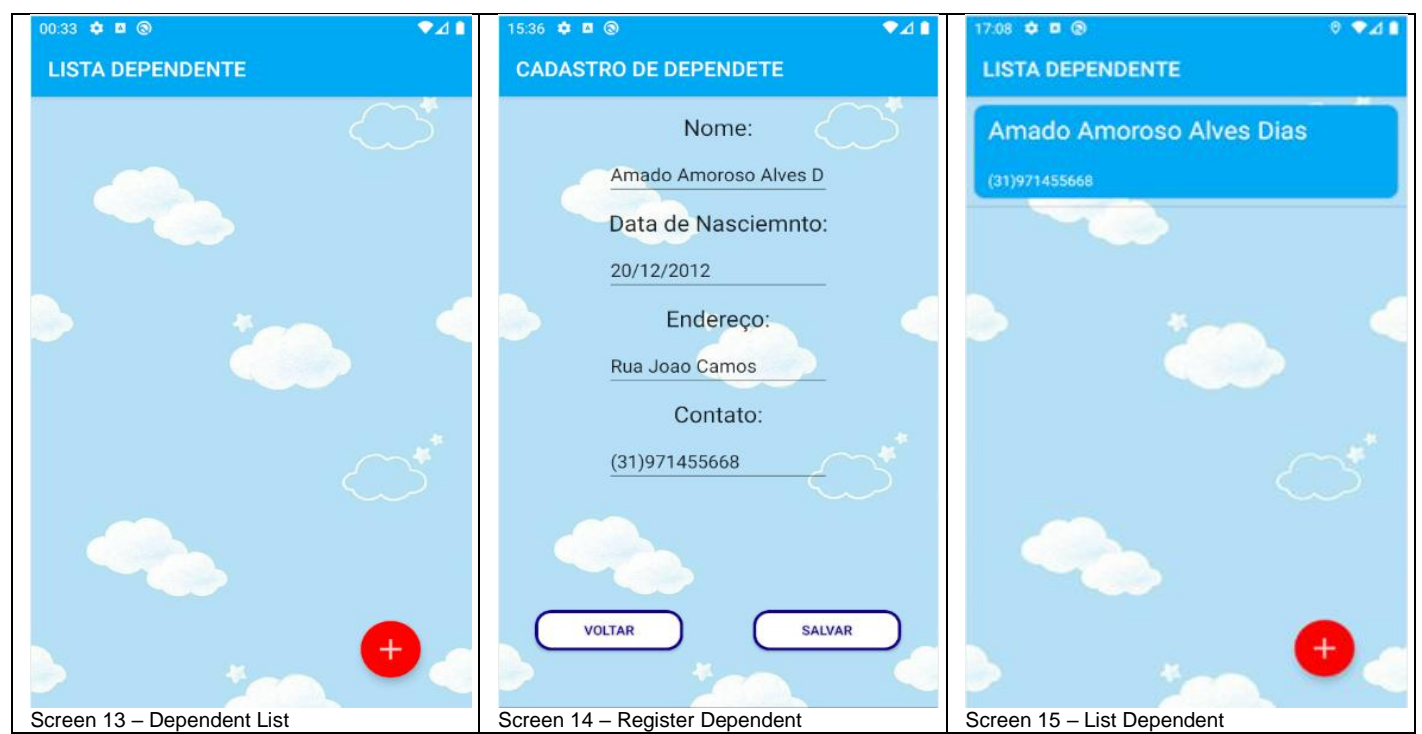

Source: Authors, 2020

Table 3: Screenshots of the application screens (part 3)

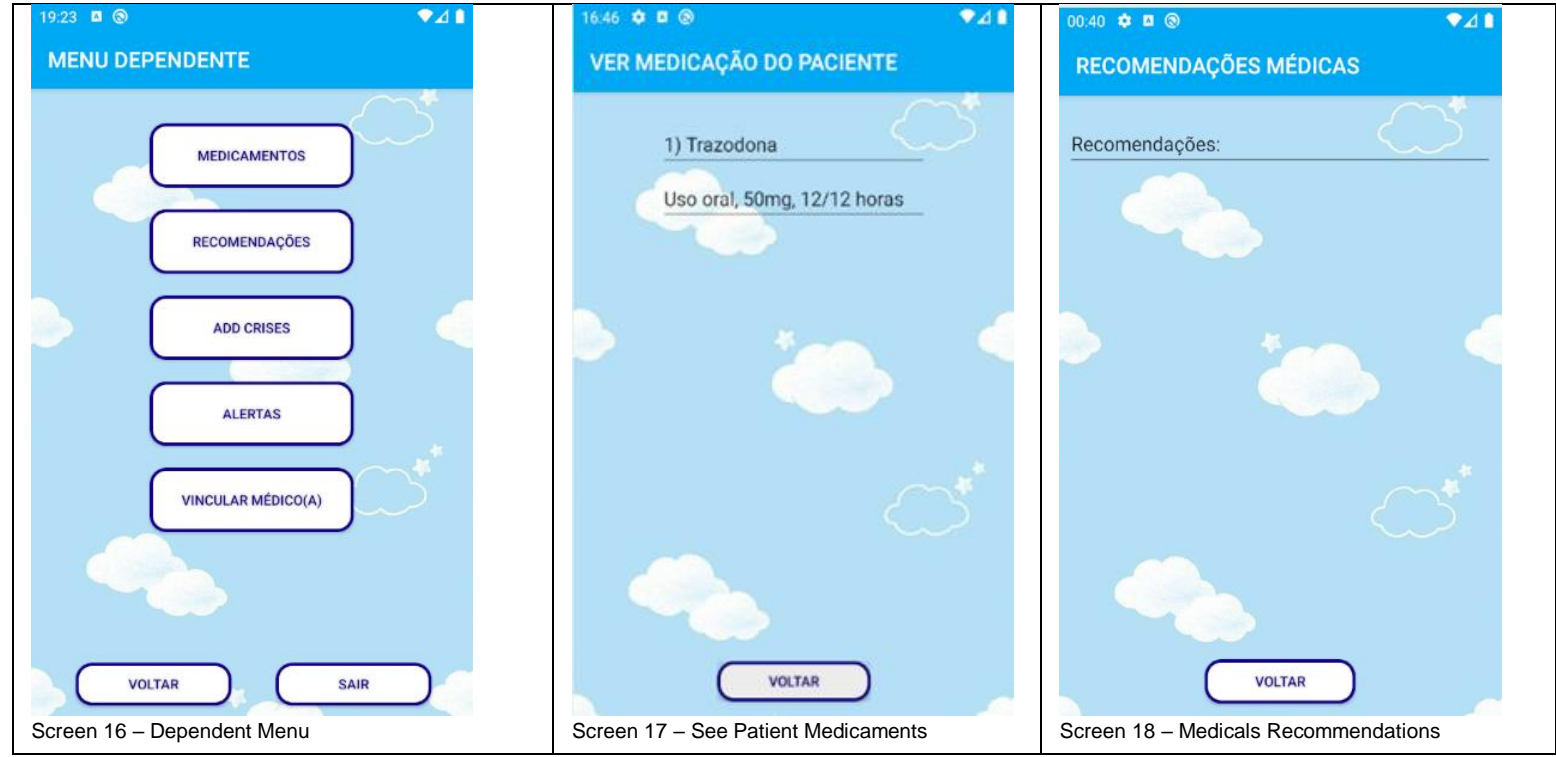




\section{$3^{\text {rd }}$ International Conference on Research in SCIENCE, ENGINEERING AND TECHNOLOGY}

\section{(ciset}

11-13 March, 2021

Oxford - United Kingdom

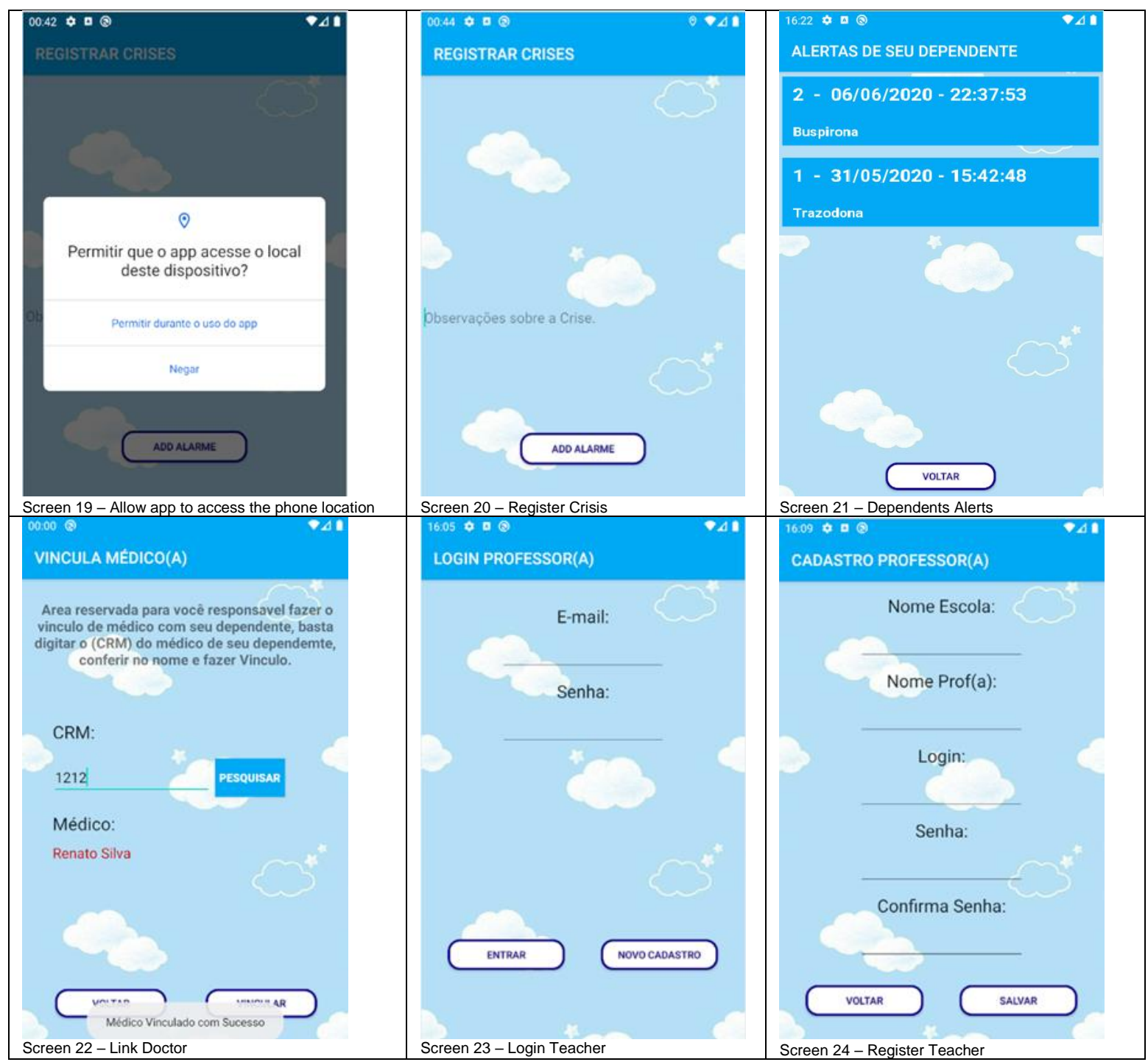

Source: Authors, 2020 


\section{$3^{\text {rd }}$ International Conference on Research in SCIENCE, ENGINEERING AND TECHNOLOGY}

11-13 March, 2021

Oxford - United Kingdom

Table 4: Screenshots of the application screens (part 4)

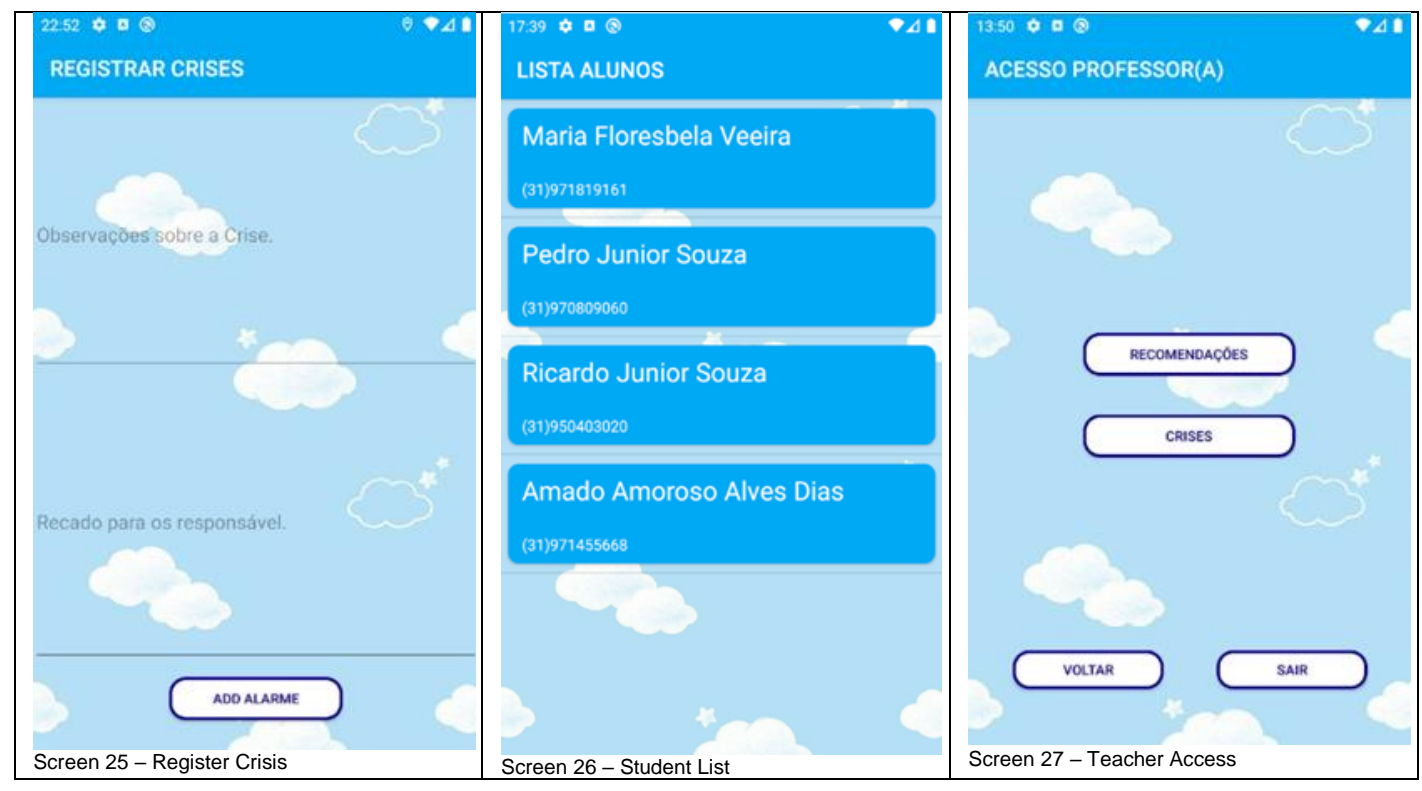

Source: Authors, 2020

\subsection{Cloud Computing-Based Infrastructure}

Google's Firebase, the Firestore cloud, was used to store the information, being possible to use it on the main mobile platforms, such as iOS, Android or on the web.

In addition, it generates different benefits that allow the development of the functioning and management of databases in an agile and effective way, with the main objective being to improve the performance of apps by implementing various features that will make the application a much more flexible tool, secure and easily accessible to users.

Firebase provides dynamic user interaction using Firebase Authentication, which allows to make the security authentications implemented by Google, one of the largest companies in the world. The application has also the capability of sending notifications to several platforms with Cloud Messaging.

With this tool the application is able to notify the doctor after configuring the alert traffic light. When the first crisis of the patient occurs, as soon as registered in the bank, Cloud Messaging sends a notification to the doctor linked to that patient. For instance, a status change from green to yellow will generate a second notification to the doctor through the application, leaving the doctor aware that their patient has left the stable state, if the patient turns on the red light, at each new crisis the doctor will be notified.

With the Cloud Messaging functionality, the guardian will be notified whenever a crisis occurs at the school, in addition to the notification that their dependent had a crisis, it will be possible for the teacher to send a message to the guardian. 


\subsection{Data Analysis}

With the interaction of the parties closest to the TEA carrier, it provides a more assertive data collection, with the information collected from the patient at the time of the crises. The crisis that will be counted considering the real time by date and time storage during the, observation of the crisis and also what the patient was doing at the time the crisis occurred, will be collected by the application for analysis and decision making. As can be seen, in figures 5 to 7 , the graphs show the total number of crises and schedules, with a daily, weekly and monthly horizon.

Figure 5: Daily Crisis Graph Example

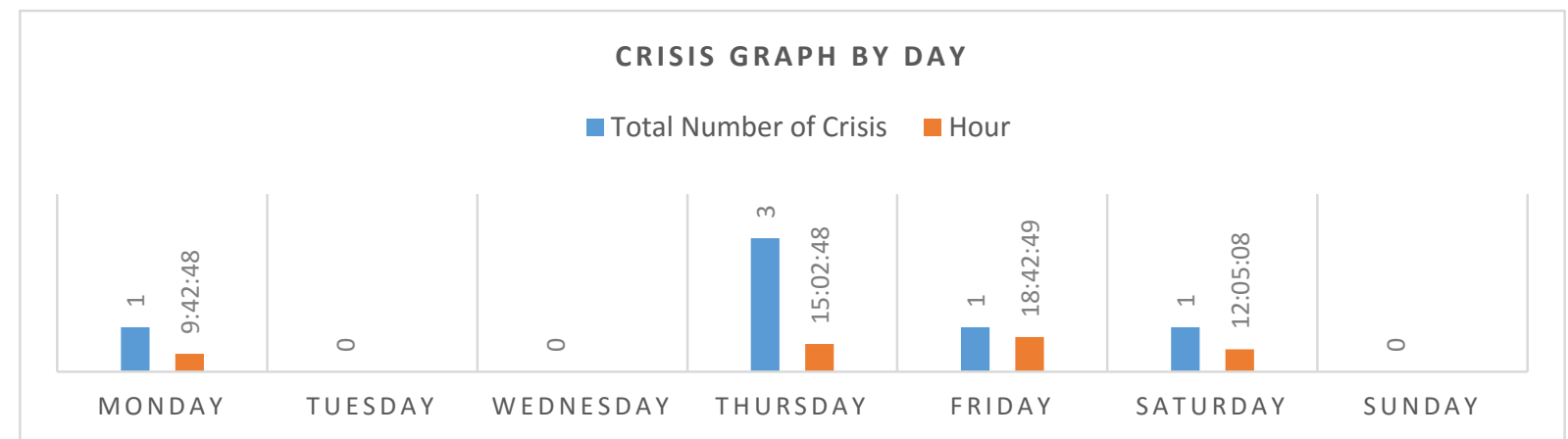

Source: Authors, 2020

Figure 6: Crisis Graph Example (Weekly Average)

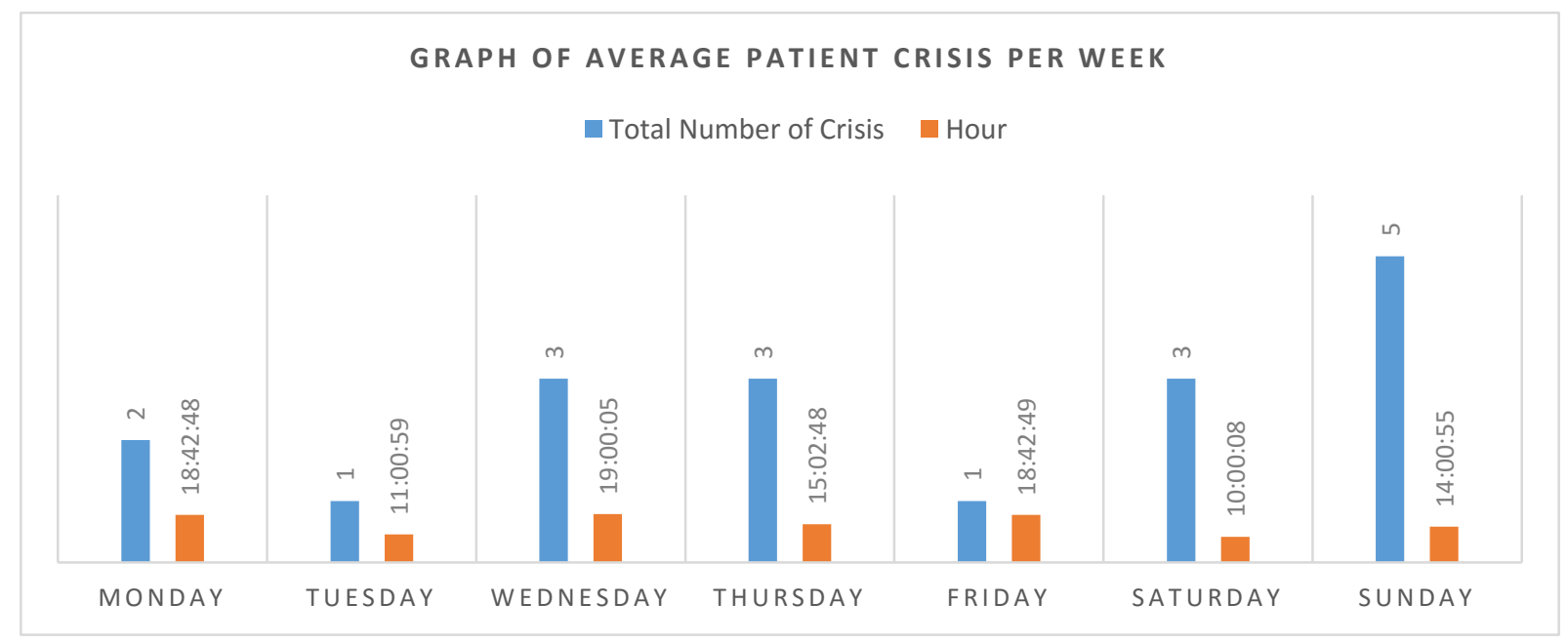

Source: Authors, 2020 


\section{$3^{\text {rd }}$ International Conference on Research in SCIENCE, ENGINEERING AND TECHNOLOGY}

11-13 March, 2021

Oxford - United Kingdom

Figure 7: Graphical Crisis Example (Monthly Average)

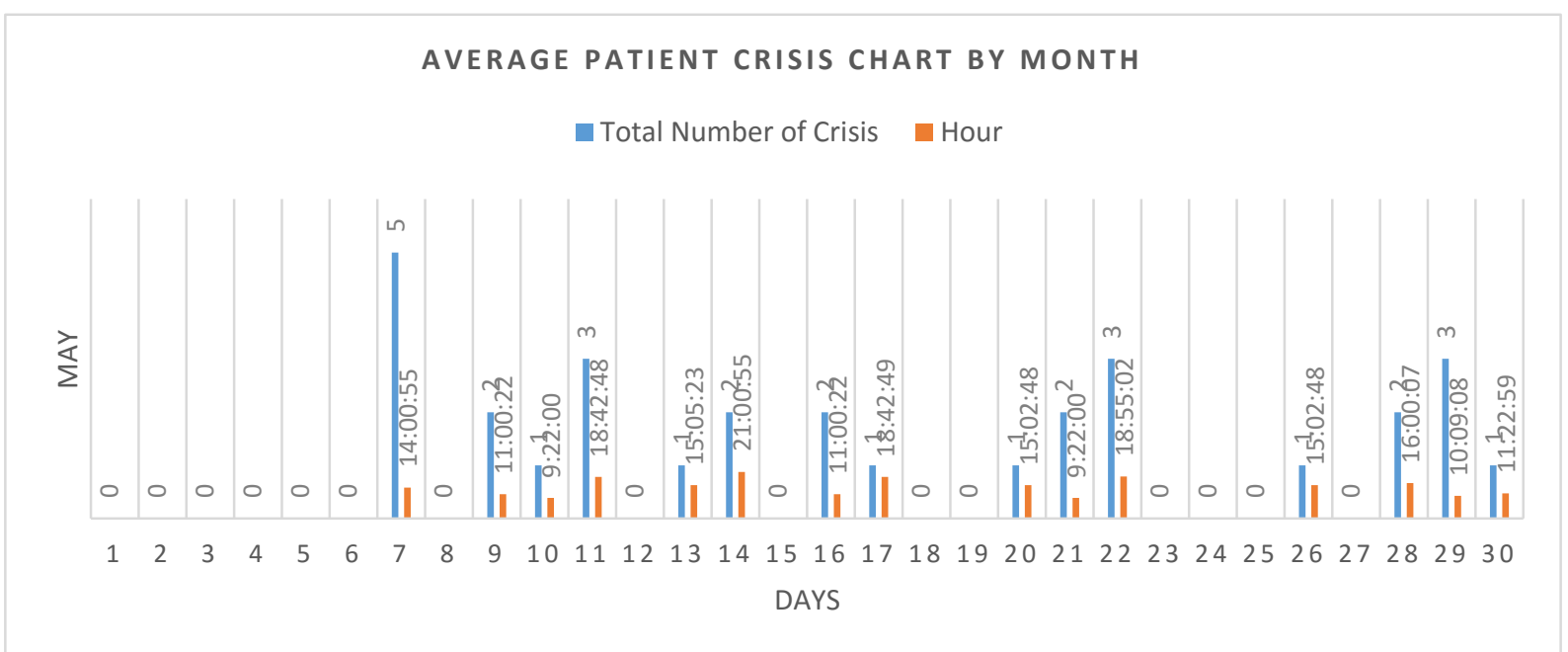

Source: Authors, 2020

In these charts, consolidated in the cloud according to the storage of the database, it is possible to view the accounting of crises, with a calculation of the average time of occurrence, according to the evaluated time horizon. Samples are fictitious, just to prove functionality.

\subsection{Future Expansions}

With the structure developed, some studies were made possible, which depend on the population of the databases, however, they are perfectly plausible and useful for the management of patient treatment, such as:

- Geolocation: with the location of crisis occurrences, it is possible to have a more assertive analysis about the locations of the occurrences, in order to define the environments that may (or may not) influence a crisis;

- Machine Learning: as the database grows, it is possible, in the future, that pattern recognition algorithms can guide predictions of crisis occurrences;

- Fuzzy logic: with the assessment of crisis levels, a study on the degree of crisis that can occur, under some circumstances, can be studied.

Such studies will be feasible as soon as a robust quantity (thousands) of samples is collected.

\section{Conclusion}

With the structure developed, it was possible for a mobile tool to reach a viability that can help decision making in a type of situation that afflicts several families. 


\section{$3^{\text {rd }}$ International Conference on Research in SCIENCE, ENGINEERING AND TECHNOLOGY}

11-13 March, 2021

Oxford - United Kingdom

The application can make data collections more accurate, in different environments, with a resource fully available in society, in addition to enabling a more realistic analysis of the occurrences with the patient.

Finally, it could be seen that, with a long-term use of the proposed solution, the technologies that permeate the ability to predict, can connect with the presented structure. Interconnected, these technologies can guide, in the future, the ability to predict patient crises, figuring a contribution for the families who experience the studied situation.

\section{References}

[1] Loncar-Turukalo, T., Zdravevski, E., da Silva, J. M., Chouvarda, I. and Trajkovik, V. (2019). Literature on wearable technology for connected health: Scoping review of research trends, advances, and barriers. Journal of medical Internet research, 21(9), e14017.

[2] Stoyanov, S. R., Hides, L., Kavanagh, D.J., Zelenko, O., Tjondronegoro, D. and Mani, M. (2015). Mobile app rating scale: a new tool for assessing the quality of health mobile apps. JMIR mHealth and uHealth, v. 3, n. 1, p. e27.

[3] Meyer, N., Kerz, M., Folarin, A., Joyce, D. W., Jackson, R., Karr, C., Dobson, R. and Maccabe, J. (2018) Captura de perfis de atividades de descanso na esquizofrenia usando tecnologias móveis e vestíveis: desenvolvimento, implementação, viabilidade e aceitabilidade de uma plataforma de monitoramento remoto. JMIR mHealth e uHealth, v. 6, n. 10, p. e188.

[4] Varghese, B. and Buyya, R. (2018) Next generation cloud computing: New trends and research directions. Future Generation Computer Systems, v. 79, p. 849-861.

[5] Onzi, F. Z. and Gomes, R. D. F (2015) Transtorno do Espectro Autista: a importância do diagnóstico e reabilitação. Revista Caderno Pedagógico, v. 12, n. 3.

[6] Sim, I. (2019). Mobile devices and health. New England Journal of Medicine, 381(10), 956968. 